\title{
ASSOCIATION OF SOME SOCIO-ECONOMIC AND SOCIO- DEMOGRAPHIC VARIABLES WITH WASTING AMONG PRE- SCHOOL CHILDREN OF NORTH BENGAL, INDIA
}

\author{
Pushpa Lata Tigga', Jaydip Sen, Nitish Mondal ${ }^{2}$
}

\begin{abstract}
BACKGROUND: Undernutrition is a global public health problem that causes premature morbidity and ill-health conditions and has long-lasting physiological effects in children. The present study assesses the prevalence of wasting [low mid-upper arm circumference (MUAC)-for-age] among children and to determine the association of wasting with different socio-economic and socio-demographic variables. METHODS: The present cross-sectional study was conducted among 1222 pre-school children (boys: 589; girls: 633), aged 1-5 years, in Darjeeling district, North Bengal, India, using multistage stratified random sampling method. The MUAC was measured using the standard anthropometric procedure. Low $M U A C$-for-age was assessed by comparing with a standard age-sex-specific reference population (WHO, 1995). Children with MUAC value were found to be the z-scores $<-3 S D$, and $<-2 S D$ were considered to be severely and moderately wasted, respectively. The socio-economic and socio-demographic variables were recorded using structured schedule methods. The data were statistically analyzed based on descriptive statistics, chi-square analysis and logistic regression using SPSS (version, 17.0).

RESULTS: The age-specific mean MUAC ranged from 126.1-142.5 $\mathrm{mm}$ (boys) and 126.9-136.4 mm (girls). The prevalence of wasting was very high (boys: 62.3\%; girls: 63.3\%) (p>0.05). The logistic regression analysis observed that age, gender, birth order, area (rural), maternal education, household income and mothers' age were significantly associated with the prevalence of wasting $(p<0.05)$.

CONCLUSION: Using MUAC-for-age, a high prevalence of wasting was observed among the children. Birth order, maternal education and maternal occupation were important determinants of wasting. There is an urgent requirement of nutritional intervention programmes to ameliorate the nutritional status of the children.

KEYWORDS: Malnutrition, Child health, Under Five, Anthropometry, Wasting, Mid upper Arm Circumference, Birth Order, Maternal Education
\end{abstract}

DOI: http://dx.doi.org/10.4314/ejhs.v25i1.9

\section{INTRODUCTION}

Many developing countries have experienced rapid economic, demographic and nutritional transitions in recent decades, resulting in changes in dietary habits, nutritional status and lifestyles $(1,2)$. Undernutrition is a global public health problem considered to be a principal cause of illhealth and premature morbidities. It is estimated that a total of 162 million and 99 million children aged $<5$ years were stunted and underweight in 2012, respectively (3). Undernutrition is also a cause of high child mortality and has long-lasting physiological effects on children $(2,4)$. It is also considered to have critical adverse health effects among those children who survive to adulthood $(4,5)$. Despite economic developments, child undernutrition still remains a major public health

\footnotetext{
${ }^{1}$ Department of Anthropology, University of North Bengal, Raja Rammohunpur, Darjeeling, West Bengal, India,

${ }^{2}$ Department of Anthropology, Assam University (Diphu Campus), Diphu, Karbi Anglong, Assam, India

Corresponding Author: Dr. Nitish Mondal, Email: nitish_slg@ rediffmail.com
} 
issue in India $(4,6-9)$, whose underlying cause is considered to be poverty $(2,8,10-11)$. The country has shown the highest occurrence of child undernutrition in the world and has been estimated that more than half of the children are undernourished (2,10,11). Another important phenomenon studies have reported is the discrimination against the female child that they were more nutritionally vulnerable than boys (7-9). Child undernutrition is influenced by several socioeconomic and socio-demographic variables (e.g., sex, age, birth order, education and occupation) $(6,8,9,12,13)$.

Anthropometry is the single most universally applicable non-invasive and inexpensive technique that is available to researchers focusing on nutrition assessment $(5,7,8,9,14,15)$. Several anthropometric measures such as stunting (low height-for-age), wasting (low weight-for-height) and underweight (low weight-for-age) have been extensively used to assess undernutrition among children $(5,7,8,9,16)$. These measures reflect distinct biological processes of human life, and their usages are very important for determining appropriate nutritional interventions. However, it has also been argued that these conventional anthropometric measures are considered to be overlapping in nature and unable to assess the actual magnitude of undernutrition $(4,9,17)$. The Mid Upper Arm Circumference (MUAC) is considered to be an easy and quick tool for the assessment of undernutrition suitable for community and clinical investigations. The main advantage of MUAC is its simplicity and that it is generally used as a proxy screening measure of wasting (low MUAC-for-age) (5,13,16,18-19). Recently, the World Health Organization (WHO) has developed age-sex specific MUAC cut-offs to determine the prevalence of undernutrition among pre-school children $(<5$ years) $(5,16,20)$. The preschool children are one of in the major nutritionally vulnerable target group, and researches have reported a greater magnitude of undernutrition utilized MUAC (13,18,19,21-31).

The prevalence of undernutrition among children leads to disease related mortality and slow cognitive development in children. Therefore, the assessment of their nutritional status assumes an immediate priority and is a daunting task for any researcher focusing on epidemiological investigations. A comparison between the standard conventional weight and height related anthropometric indices such as height-for-age and weight-for-age, and MUAC shows that the latter is a more valuable, reliable, low-cost independent indicator to determine undernutrition among preschool children (20,32-35).

Given the above facts, the objectives of the present study are as follows:

a) To assess the prevalence of undernutrition (wasting) using the MUAC-for-age cut-offs among children aged 1-5 years from North Bengal, India;

b) To observe the association of different socioeconomic and socio-demographic variables on the prevalence of wasting among children.

\section{MATERIALS AND METHODS}

The northern part of the state of West Bengal, India, is popularly known as North Bengal and consists of six districts. The area chosen for the present study is located in the Darjeeling district of this region. A number of tribal communities (Rabha, Meche, Toto, Oraon, Santal and Munda), and non-tribal communities (Rajbanshi, Bengali Caste and Bengali Muslims) reside in this area. Given the area's general backwardness, the communities of the region remain vulnerable to undernutrition $(8,9,14,15,17)$. This cross-sectional study was carried out among pre-school children aged 1-5 years and residing in a rural and an urban habitat of Darjeeling District. The children covered in the study belonged to the Proto-Australoid Tribal Populations (Oraon, Santal and Munda) and the Bengali Hindu Caste Population (BHCP), the natures of which are described elsewhere $(8,36)$. The data were recorded from the children when they visited different centres of the Integrated Child Development Scheme (ICDS) of the Government of India and also by household visits. A total of 24 ICDS centres located both in rural and urban regions of Matigara Block in the Darjeeling District were covered. The beneficiaries of the scheme are pre-school children, pregnant and lactating mothers and women in the age group of 15-44 years and the largest national program for promotion and development of health of the mother and child. The ICDS scheme provides non-formal pre-school education, supplementary nutrition, immunization, health check-up, referral services, nutrition and health education $(7,25)$. The children were selected using a multi-stage stratified random sampling method. Initially 1303 children (boys: 626; girls: 
677) were selected to take part in the study. The age and ethnicity of these children were determined from the ICDS and official records. However, 81 of them (boys: 37; girls: 44) were excluded from the study as either their dates of birth were not available or they did not belong to the age group selected. The final sample consisted of 1222 children (boys: 589; girls: 633). All the children were free from any physical deformities and were not suffering from any diseases at the time of data collection. Prior to data collection, Permissions for the study were taken from the ICDS centres and local Panchayets (a village level governing authority). An informed consent was also obtained from the parents of the children. The research approval and ethical clearance were obtained from the University of North Bengal. The study was conducted in accordance with the ethical guidelines for human experiments as laid down in the Helsinki Declaration of 2000 (37).

Anthropometric measurements recorded: The MUAC was obtained following the standard anthropometric procedure (38). It was measured at the point midway between the acromion and the radiale of the upper-arm using a plastic coated nonstretchable measuring tape on the left side of each subject to the nearest $1 \mathrm{~mm}$. The intra-observer and inter-observer technical errors of the measurements (TEM) were calculated for testing the co-efficient of reliabilities (39). For this, MUACs were recorded from 50 children other than those selected for the study by two trained authors in field investigation and anthropometric data collection (PT and JS). Very high values of $R(>0.97)$ were obtained for TEM and these values were observed to be within the recommended cut-offs value $(r=0.95)$ (39). Hence, the measurements recorded by both authors were considered reliable and reproducible. Subsequently, all the measurements in the course of the present study were recorded by one of the authors (PT).

Socio-economic and socio-demographic data recorded: The socio-economic and sociodemographic variables were recorded using interview and schedule methods by visiting the ICDS centres and the households of the children. Parents of the children were interviewed to obtain the necessary information. A modified version of the scale of Kuppuswamy was utilized to ascertain the socioeconomic status (SES) of the children (40). Based on the above scale, all the children in the present study belonged to a lower socio-economic group. The data recorded were sex, age, birth order, study area, father's education, mother's education, ethnic group, toilet facility, electricity, father's occupation, mother's occupation and household income.

Assessment of nutritional status: The prevalence of low MUAC-for-age was assessed by comparing the results with the age- and sex-specific reference population of WHO (5). The severity of undernutrition was assessed by utilizing the $\mathrm{z}$-score based classification. Children with age-sex specific MUAC value $<-3$ SD and $<-2$ SD were considered as severely and moderately wasted, respectively $(5,16,20)$. The classification used to identify the severity of wasting based on the percentages of the prevalence of wasting was low $(<5.00 \%)$, medium $(5.00 \%-9.00 \%)$, high $(10.00 \%-14.00 \%)$ and very high $(\geq 15.00 \%)(5)$.

Statistical Analysis: The statistical analysis was carried out using the Statistical Package for Social Sciences (SPSS; version 17.0). Chi-square $\left(\chi^{2}\right)$ analysis was utilized to assess the differences between sexes in the moderate and severe categories of wasting. The prevalence in different socio-economic and socio-demographic and lifestyle variables was also assessed using $\chi^{2}$ analysis. A logistic regression using maximum likelihood estimation model was fitted to estimate the odds of being affected by wasting as this univariate model allows the creation of categorical depended variables and the odds were obtained by comparing with reference category. The predictor variables were sex, age, birth order, study area, father's education, mother's education, ethnic group, toilet facility, electricity, father's occupation, mother occupation and household income. In this model, children who were both moderately $(<-$ 2SD) and severely $(<-3 \mathrm{SD})$ undernourished were considered under the combined categories of undernutrition $(<-2 \mathrm{SD})$. Therefore, children belonging to undernourished group $(<-2 \mathrm{SD})$ were coded as ' 0 ' and those with the higher or equal to 2 SD (normal) were coded as ' 1 '. These values were entered into the logistic regression model as response variables instead of the actual z-score values. Similarly, the predictor variables were coded separately and entered into the regression model as a set of dummy variables. A p-value $<0.05$ was considered statistically significant. 


\section{RESULTS}

The age- and sex-specific distribution, descriptive statistics and prevalence of wasting among the children is depicted in Table 1 . The overall and agespecific mean MUAC was observed to be greater among boys than girls, except in case of 1 year and 4 years $(\mathrm{p}<0.05)$. The age and sex-specific mean MUAC gradually increased with age, with an exception among girls aged 2 years. The agespecific mean MUAC ranged from $126.1 \mathrm{~mm}$ to $142.5 \mathrm{~mm}$ among 1 year to 5 years (in boys) and $126.9 \mathrm{~mm}$ to $136.4 \mathrm{~mm}$ among 1 year to 5 years (in girls) respectively. The overall sex-difference in mean MUAC was observed to be statistically significant $(\mathrm{F}=7.64$; d.f.: 1,$1221 ; \mathrm{p}<0.05)$. The sexspecific mean MUAC differences were also statistically significant $(\mathrm{p}<0.01)$ except in case of 1 year $(\mathrm{F}=0.19$; d.f.: 1,1221$)$ and 4 years $(\mathrm{F}=0.01 ;$ d.f.: 1,1221$)(\mathrm{p}>0.05)$ (Table 1).

Prevalence of wasting using MUAC-for-Age: The overall prevalence of wasting was $62.3 \%$ and $63.3 \%$ among the boys and girls, respectively $(\mathrm{p}<0.01) \quad($ Table 1). The overall age-specific prevalence of wasting did not indicate any general trend, but the prevalence of moderate and severe wasting was greater among 5 years $(42.0 \%)$ and 3 years $(29.3 \%)$ old children, respectively. Moderate wasting was greater among boys $(38.4 \%)$ as compared to girls $(37.0 \%)$, but severe wasting was greater among girls $(26.4 \%)$ than boys $(23.9 \%)$. The sex-specific overall moderate prevalence of wasting was not, however, statistically significant ( $p>0.05$ ). The age-specific prevalence of moderate and severe wasting did not exhibit any general trend among the children, but it was seen that boys were more affected than girls. The age-specific greatest prevalence of moderate wasting was among boys aged 2 years and girls aged 3 years. A lower prevalence of moderate wasting was observed among both boys and girls aged 1 year. The age and sex-specific prevalence of severe wasting ranged from $7.3 \%$ (5 years) to $32.5 \%$ (1 year) among boys and $20.2 \%$ (in 1 year) to $34.3 \%$ (in 2 years) among girls. The age and sex-specific differences were statistically not significant in both moderate and severe wasting using $\chi^{2}$ analysis ( $\left.\mathrm{p}>0.05\right)$.

Associations between wasting and socio-economic and socio-demographic variables: The $\chi^{2}$ analysis showed that the prevalence of wasting between the different socio-economic and socio-demographic variables were observed to be statistically not significant $(p>0.05)$ (Table 2). The results of the logistics regression analysis showed that children aged 2 years and 3 years exhibited significant 1.5 times greater odds for being wasted $(p<0.05)$. Girls exhibited a slightly greater risk to wasting as compared to boys ( $p>0.05)$. Children belonging to the $\geq 3^{\text {rd }}$ birth orders and those residing in rural areas also exhibited significantly 1.40 times and 1.64 times risks of being wasted $(p<0.05)$. There also appeared to be an ethnic effect on the prevalence of wasting, with the BHCP children exhibiting 1.35 times greater odds of being wasted $(p<0.05)$. Children of illiterate mothers and those of mothers with primary education had 1.64 times and 1.51 times greater risks of wasting $(p<0.05)$, respectively. Children were belonging to the families where the household income of Rs. 20014000 had 1.35 times greater odds of being wasted $(\mathrm{p}<0.05)$. The association of toilet facility, electricity facility, father's education and father's and mother's occupation did not exhibit any statistically significant differences in the prevalence of wasting among the children ( $p>0.05)$. However, the odds of wasting were insignificantly greater in children belonging to the illiterate fathers and fathers with primary education, manual worker group and those having no electricity and toilet facilities $(\mathrm{p}>0.05)$ (Table 2).

\section{DISCUSSION}

The legacy of undernutrition, especially among preschool children is considered as a major public health issue and cause a huge burden to overall national development. The foremost aim of nutritional assessment studies is to determine the actual magnitude of undernutrition and thereby introduce appropriate nutritional intervention programmes to improve the existing nutrition situation $(5,16,20)$. Assessments of undernutrition among children bear great significance in developing countries such as India, where the vast majority of the populations remain undernourished and underprivileged (2,7-10). Studies have reported that MUAC is a very important anthropometric measure for assessment of undernutrition because it showed a good correlation with body mass index and an easy-to-use measurement to record both during emergencies and nutritional surveys $(5,41)$. A comparison of wasting among children belonging to different tribal, non-tribal and non-Indian populations is depicted in Table 3 . The overall 
Table 1: Age sex-specific mean \pm SD and prevalence of wasting based on MUAC among the children

\begin{tabular}{|c|c|c|c|c|c|c|c|c|c|c|c|c|c|c|c|}
\hline \multirow[t]{3}{*}{ Age } & \multicolumn{3}{|c|}{ Number of samples } & \multicolumn{3}{|c|}{ MUAC (mm) } & \multicolumn{9}{|c|}{ Prevalence of wasting (low MUAC-for-age) } \\
\hline & \multirow[b]{2}{*}{ Boys } & \multirow[b]{2}{*}{ Girls } & \multirow[b]{2}{*}{ Total } & \multirow{2}{*}{$\begin{array}{c}\text { Boys } \\
\text { Mean } \pm \text { SD }\end{array}$} & \multirow{2}{*}{$\begin{array}{l}\text { Girls } \\
\text { Mean } \pm \text { SD }\end{array}$} & \multirow{2}{*}{$\begin{array}{l}\text { Sex } \\
\text { difference } \\
\text { (F-value) }\end{array}$} & \multicolumn{3}{|c|}{ Boys } & \multicolumn{3}{|c|}{ Girls } & \multicolumn{3}{|c|}{ Overall } \\
\hline & & & & & & & -2 SD & -3 SD & Total & -2 SD & $-3 \mathrm{SD}$ & Total & $-2 S D$ & $-3 S D$ & Total \\
\hline 1 year & 123 & 124 & 247 & $126.1 \pm 15.6$ & $126.9 \pm 14.7$ & 0.19 & $39(31.7)$ & $40(32.5)$ & $79(64.2)$ & $40(32.2)$ & $25(20.2)$ & $65(52.4)$ & $79(32.0)$ & $65(26.3)$ & $144(58.3)$ \\
\hline 2 year & 120 & 137 & 257 & $131.7 \pm 13.3$ & $127.0 \pm 15.4$ & $7.22 * *$ & $53(44.2)$ & $27(22.5)$ & $80(66.7)$ & $45(32.8)$ & $47(34.3)$ & $92(67.2)$ & $98(38.1)$ & $74(28.8)$ & $172(66.9)$ \\
\hline 3 year & 125 & 128 & 253 & $132.9 \pm 13.7$ & $129.8 \pm 14.8$ & $2.85^{*}$ & 49(39.2) & $35(28.0)$ & $84(67.2)$ & $52(40.6)$ & $39(30.5)$ & $91(71.1)$ & 101(39.9) & $74(29.3)$ & $175(69.2)$ \\
\hline 4 year & 125 & 138 & 263 & $135.4 \pm 13.7$ & $135.5 \pm 16.0$ & 0.01 & $46(36.8)$ & $32(25.6)$ & $78(62.4)$ & $51(37.0)$ & $32(23.2)$ & $83(60.1)$ & $97(36.9)$ & $64(24.3)$ & $161(61.2)$ \\
\hline 5 year & 96 & 106 & 202 & $142.5 \pm 10.3$ & $136.4 \pm 12.4$ & $14.13 * *$ & $39(40.6)$ & $7(7.3)$ & $46(47.9)$ & $46(43.4)$ & $24(22.6)$ & $70(66.0)$ & $85(42.0)$ & $31(15.3)$ & $116(57.4)$ \\
\hline Total & 589 & 633 & 1222 & $133.3 \pm 14.5$ & $131.0 \pm 15.3$ & $7.64 * *$ & $226(38.4)$ & 141(23.9) & $367(62.3)$ & $234(37.0)$ & $167(26.4)$ & $401(63.3)$ & $460(37.6)$ & $308(25.2)$ & $768(62.9)$ \\
\hline
\end{tabular}

Figures in parenthesis indicate percentage *p<0.05, **p<0.01, SD: standard deviation

Table 2: Results of logistic regression analysis and profile of socio-economic and socio-demographic variables with the prevalence of wasting (<-2SD) among the children

\begin{tabular}{|c|c|c|c|c|c|c|c|c|c|}
\hline \multirow[t]{2}{*}{ Category } & \multirow[t]{2}{*}{ Sub-category } & \multirow[t]{2}{*}{$\mathbf{N}$} & \multicolumn{2}{|c|}{ Wasting $(<-2 S D)$} & \multicolumn{5}{|c|}{ Logistic regression analysis } \\
\hline & & & Prevalence & Chi-value & $\mathbf{B}$ & SE & Crude Odds & $\mathbf{p}$ & $95 \% \mathrm{CI}$ \\
\hline \multirow[t]{2}{*}{ Sex } & Male ® & 589 & $367(47.8)$ & $0.03 *$ & - & - & - & - & - \\
\hline & Female & 633 & $401(52.2)$ & & 0.045 & 0.118 & 1.05 & 0.707 & $0.83-1.32$ \\
\hline \multirow[t]{5}{*}{ Age } & 1 year & 247 & $144(18.8)$ & $2.54 *$ & 0.036 & 0.192 & 1.04 & 0.852 & $0.71-1.51$ \\
\hline & 2 year & 257 & $172(22 . .4)$ & & 0.406 & 0.194 & 1.50 & 0.037 & $1.03-2.20$ \\
\hline & 3 year & 253 & $175(22.8)$ & & 0.509 & 0.197 & 1.66 & 0.010 & $1.13-2.45$ \\
\hline & 4 year & 263 & $161(21.0)$ & & 0.157 & 0.190 & 1.17 & 0.409 & $0.81-1.70$ \\
\hline & 5 year $®$ & 202 & $116(15.1)$ & & - & - & - & - & - \\
\hline
\end{tabular}




\begin{tabular}{|c|c|c|c|c|c|c|c|c|c|}
\hline 68 & iop J Health Sci. & & ol. 25, No. 1 & & & & & & \\
\hline \multirow[t]{3}{*}{ Birth order } & $1 \AA$ & 393 & $236(30.7)$ & $1.30 *$ & - & - & - & - & - \\
\hline & 2 & 459 & $281(36.6)$ & & 0.049 & 0.141 & 1.05 & 0.728 & $0.80-1.38$ \\
\hline & $3 \geq$ & 370 & $251(32.7)$ & & 0.339 & 0.152 & 1.40 & 0.025 & $1.04-1.89$ \\
\hline \multirow[t]{2}{*}{ Study area } & Rural & 993 & $646(84.1)$ & $2.65^{*}$ & 0.490 & 0.148 & 1.63 & 0.001 & $1.22-2.18$ \\
\hline & Urban ${ }^{\circledR}$ & 229 & $122(15.9)$ & & - & - & - & - & - \\
\hline \multirow{3}{*}{$\begin{array}{l}\text { Mother } \\
\text { education }\end{array}$} & Illiterate & 646 & 417 (54.3) & $1.25^{*}$ & 0.496 & 0.219 & 1.64 & 0.024 & $1.07-2.53$ \\
\hline & Upto primary & 479 & $300(39.1)$ & & 0.413 & 0.224 & 1.51 & 0.041 & $0.97-2.35$ \\
\hline & $\geq$ Secondary ${ }^{\circledR}$ & 97 & $51(6.6)$ & & - & - & - & - & - \\
\hline \multirow{3}{*}{$\begin{array}{l}\text { Father } \\
\text { education }\end{array}$} & Illiterate & 388 & $238(31.0)$ & $0.27 *$ & 0.002 & 0.183 & 1.00 & 0.991 & $0.70-1.44$ \\
\hline & Upto primary & 648 & $416(54.2)$ & & 0.124 & 0.171 & 1.13 & 0.468 & $0.81-1.59$ \\
\hline & $\geq$ Secondary ${ }^{\circledR}$ & 186 & $114(14.8)$ & & - & - & - & - & - \\
\hline \multirow[t]{2}{*}{ Ethnic group } & BHCP $®$ & 628 & $416(54.2)$ & $1.46^{*}$ & 0.299 & 0.119 & 1.35 & 0.012 & $1.07-1.70$ \\
\hline & Tribal & 594 & $352(45.8)$ & & - & - & - & - & - \\
\hline Toilet & No & 550 & $350(45.6)$ & $0.06^{*}$ & 0.061 & 0.119 & 1.06 & 0.606 & $0.84-1.34$ \\
\hline facility & Yes ${ }^{\circledR}$ & 672 & $418(54.4)$ & & - & - & - & - & - \\
\hline \multirow[t]{2}{*}{ Electricity facility } & No & 265 & $167(21.7)$ & $0.01 *$ & 0.009 & 0.144 & 1.01 & 0.948 & $0.76-1.34$ \\
\hline & Yes ® & 957 & $601(78.3)$ & & - & - & - & - & - \\
\hline Mothers & Housewife ® & 718 & $479(62.4)$ & $2.57 *$ & - & - & - & - & - \\
\hline Occupation & Manual worker & 504 & $289(37.6)$ & & -0.399 & 0.120 & 0.67 & 0.001 & $0.53-0.85$ \\
\hline Father & Manual worker & 955 & $607(79.0)$ & $0.01 *$ & 0.138 & 0.142 & 1.15 & 0.330 & $0.87-1.52$ \\
\hline occupation & Others ${ }^{\circledR}$ & 267 & $161(21.0)$ & & - & - & - & - & - \\
\hline Household Income & $\leq$ Rs. 2000 & 197 & $124(16.1)$ & $0.92 *$ & 0.232 & 0.198 & 1.26 & 0.240 & $0.86-1.86$ \\
\hline \multirow[t]{2}{*}{ [Rupees(Rs)] } & Rs.2001-4000 & 788 & $508(66.1)$ & & 0.298 & 0.151 & 1.35 & 0.048 & $1.00-1.81$ \\
\hline & $\geq$ Rs. $4001{ }^{\circledR}$ & 237 & $136(17.7)$ & & - & - & - & - & - \\
\hline
\end{tabular}

Figures in parenthesis indicate percentages, ${ }^{\circledR}$ Reference category, *p>0.05 
Table 3: Comparison of the prevalence of wasting (low MUAC-for-age) in children aged upto 5 years

\begin{tabular}{|c|c|c|c|c|c|c|c|}
\hline Ethnic group/ population & Region/Area & Sample & Age group & $\begin{array}{l}\text { Reference/ } \\
\text { cut-offs }\end{array}$ & $\begin{array}{l}\text { Prevalence of } \\
\text { Wasting }\end{array}$ & $\chi^{2}$-value & Reference \\
\hline Bauri & Purulia, West Bengal & 499 & 2-6 years & WHO,1995 & 32.46 & $54.98 *$ & Das et al.(26) \\
\hline Santal & Purulia, West Bengal & 514 & $2-6$ years & WHO, 1995 & 33.27 & $51.90^{*}$ & Das et al. (26) \\
\hline Affluent urban & Midnapore, West Bengal & 1060 & $1-3$ years & WHO,1995 & 18.96 & $216.01 *$ & Maiti et al. (30) \\
\hline Urban poor & North 24 Parganas, West Bengal & 899 & $1-5$ years & WHO, 1995 & 77.80 & 3.43 & Bisai (24) \\
\hline Bengalee Muslims & Nadia District, West Bengal & 2016 & $3-5$ years & WHO, 1995 & 35.11 & $109.98 *$ & Biswas et al. (25) \\
\hline Rural-Urban & Cuttack, Orissa & 292 & $1-5$ years & MUAC $<13.5 \mathrm{~cm}$ & 30.32 & $40.27 *$ & Mishra and Mishra (29) \\
\hline Bengalee & Hooghly, West Bengal & 894 & $2-5$ years & WHO, 1995 & 64.54 & 0.69 & Mandal and Bose (28) \\
\hline Punjabi & Punjab, India & 6531 & $1-5$ years & WHO, 1983 & 38.52 & $122.38 *$ & Kaur et al. ( 27) \\
\hline Karbi & Karbi Anglong, Assam & 809 & $1-5$ years & WHO,2007 & 32.76 & $76.84 *$ & Mondal and Engtipi (31) \\
\hline Rural and Urban children & Kenya & 3793 & 1-5years & MUAC $<13.5 \mathrm{~cm}$ & 17.00 & $520.69 *$ & Gewa et al. (22) \\
\hline Rural Children & Banglore,Karnataka & 256 & $1-5$ years & MUAC $<13.5 \mathrm{~cm}$ & 31.00 & $35.10 *$ & Joseph et al. (35) \\
\hline School Children & Urban Ibadan,Nigeria & 319 & 1-4years & MUAC $<13.5 \mathrm{~cm}$ & 25.70 & $57.76^{*}$ & Dairo et al. (19) \\
\hline Rural and Urban children & Cetral Uganda & 261 & 1-3years & MUAC $<13.5 \mathrm{~cm}$ & 21.60 & $61.22 *$ & Kikafunda et al. (43) \\
\hline Children & Rural Kenya & 359 & 1-5years & MUAC $<11.5 \mathrm{~cm}$ & 47.00 & $12.94 *$ & Barkley et al. (32) \\
\hline Children & Mugu,Nepal & 198 & 1-4years & MUAC $<13 . .5 \mathrm{~cm}$ & 17.00 & $59.32 *$ & Sharma (44) \\
\hline Rural children & Bangladesh & 2016 & $0-5$ years & MUAC $<12.5 \mathrm{~cm}$ & 33.00 & $129.08 *$ & Choudhury et al. (18) \\
\hline Rural children & Kenya & 295 & $0-5$ years & WHO, 1995 & 26.80 & $50.76^{*}$ & Cheah et al. (12) \\
\hline Rural and sub-urban & Uganda & 261 & $0-5$ years & MUAC $<12.5 \mathrm{~cm}$ & 21.60 & $61.22 *$ & Kikafunda et al. (41) \\
\hline Rural-urban children & Darjeeling, West Bengal & 1222 & $0-5$ years & WHO, 1995 & 62.90 & - & Present study \\
\hline
\end{tabular}


prevalence of wasting in the present study was observed to be $62.9 \%$. A significantly lower prevalence of wasting among children has been reported by Kaur et al. (27) for Punjabi children $(p<0.01)$, by Chakraborty et al. (42) for Shabar children $(\mathrm{p}<0.01)$, by Mishra and Mishra (29) for rural-urban children of Odisha $(\mathrm{p}<0.01)$, by Biwas et al. (25) for Bengalee Muslim children $(\mathrm{p}<0.01)$ and by Das et al. (26) for Bauri and Santal children $(\mathrm{p}<0.01)$. A similar prevalence of wasting (64.54\%) was observed among children belonging to the Bengalee population of West Bengal (28) and children belonging to an urban population (77.80\%) of West Bengal (24) ( $p>0.05)$.

When the results of the present study were compared with available non-Indian children, a significantly greater prevalence of wasting $(\mathrm{p}<0.01)$ was observed among Ugandan $(21.60 \%)$ (43), Kenyan (47.00\%) (32), Nepalese (17.00\%) (44) and Nigerian (25.70\%) (19). Based on the WHO (5) classification of the severity of undernutrition, it has been observed that a high prevalence of wasting $(>15.00 \%)$ was observed among the tribal and non-tribal Indian children (Table 3). The present study has further observed a greater prevalence of undernutrition among girls than boys, which is consistent with the result reported in similar studies in the country (6-9). This high prevalence of undernutrition is generally attributed to a large population size, illiteracy, poverty, poor infrastructure and inappropriate healthcare facilities $(2,6,8,9,17)$. It also reflects the inadequate nutrition during early-childhood and is likely to be a consequence of well-known phenomenon of prolonged breast-feeding combined with inadequate weaning food with lower energy-density in Indian children than their non-Indian counterparts $(4,6,7,45)$.

A number of socio-economic and sociodemographic factors have been observed to have strong associations with the prevalence of undernutrition among children $(8,9,12,13,18)$. The logistic regression analysis in the present study showed that girls were 1.05 times more vulnerable than boys (Table 2). Similarly studies have reported that rural girls were more likely to be severely undernourished than boys in Bangladesh $(13,18)$. Numerous studies have also reported discriminations in diet and basic amenities against girls in India $(7-9,46)$. The results of the present study further showed that children belonging to higher age groups (e.g., 2-5 years) had a significantly greater risk odds to being wasted $(p<0.05)$, thus agreeing with the studies of Cheah et al. (12) and Choudhury et al. (18). Maternal education (such as illiterate and primary) also exhibited significantly 1.50 times greater odds to wasting $(p<0.05)$. A similar study also reported that illiterate household heads showed significantly greater risks to wasting among children $(13,18,47)$. It is also evident that children belonging to higher birth orders (e.g., >3rd) had a significantly 1.40 times greater risks for being wasted $(\mathrm{p}<0.01)$. Studies had also previously indicated that child undernutrition was strongly correlated with birth order of the children $(6,8,13$, 48). The result of the present study reveals that the risks of wasting were significantly greater in the lower income group (Rs.2000-4000) $(\mathrm{p}<0.05)$. The study further indicated that the risk of greater wasting ( $p>0.05)$ was observed among children with poor facilities such as 'no-electricity' and 'no-toilet facility' and belonging to the vulnerable segments of the population such as father's occupation being manual worker/labourer and father's education not exceeding primary level (Table 2). The existing literature also suggests that the gender differences in the prevalence of undernutrition were more pronounced in poor socio-economic groups with girls being more undernourished than boys $(6,8,12,13)$. Studies have also reported that children belonging to the economically lower segments of tribal populations were more affected by undernutrition as compared to general caste children $(6,8,9)$. The results of the present study also indicated that undernutrition remained a major problem among both tribal and non-tribal children belonging to lower socioeconomic group in India.

Generally, it must be mentioned here that due to the cross-sectional design of the present study, lack of information on dietary history, resource allocation, cultural practices and disease prevalence, it is difficult to draw a major conclusion and/or identify the actual cause(s) of such greater prevalence of wasting among children. The study has, however, highlighted that a significant proportion of the children in India were undernourished and suffering from different grades of wasting. Several socio-economic and socio-demographic factors significantly associated with the prevalence of undernutrition and birth 
order, maternal education and maternal occupation were important determinants of wasting among children. Thus regular monitoring and follow-up studies based on MUAC to assess wasting and also to monitor the efficacy of ongoing nutritional intervention programmes are recommended. There is also a need for appropriate nutritional interventions so as to ameliorate the nutritional deficiency of the children.

\section{ACKNOWLEDGEMENT}

The authors gratefully acknowledge the help and cooperation of the ICDS centers for their invaluable assistance during the study. The financial assistance of University Grants Commission in the form of a Rajiv Gandhi National Fellowship (F1-17.1/17.1/201213/RGNF-2012-2013-ST-WES-24896) is also acknowledged.

\section{REFERENCES}

1. Kolčić I. Double burden of malnutrition: A silent driver of double burden of disease in low- and middle-income countries. J Glob Health, 2012; 2: 203-03.

2. Ahmed T, Hossain M, Sanin KI. Global burden of maternal and child under-nutrition and micronutrient deficiencies. Ann Nutr Metab 2012; 61: 8-17.

3. Levels and Trends in Child Malnutrition: UNICEF-WHO-The World Bank Joint Child Malnutrition Estimates. 2012. available at: http://www.who.int/entity/nutgrowthdb/jme_unicef _who_wb.pdf.

4. Nandy S, Irving M, Gordon D, Subramanian SV, Smith GD. Poverty, child undernutrition and morbidity: new evidence from India. Bull World Health Organ, 2005; 3: 210-6.

5. World Health Organization. Physical Status: the Use and Interpretation of Anthropometry: Technical Report Series no. 854. Geneva: World Health Organization, 1995.

6. Som S, Pal M, Bhattacharya B, Bharti P. 2006. Socoeconomic differentials in nutritional status of children in the states of West Bengal and Assam India. J Bisoco Sci, 2006; 38: 625-642.

7. Bose K, Biswas S, Bisai S, Ganguli S, Khatun A, Mukhopadhyay A, et al. Stunting, underweight and wasting among Integrated Child Development Services (ICDS) scheme children aged 3-5 years of Chapra, Nadia District, West Bengal, India. Matern Child Nutr, 2007; 3: 216-221.

8. Mondal N, Sen J. Prevalence of undernutrition among children (5-12 years) belonging to three communities residing in a similar habitat in North Bengal, India. Ann Hum Biol 2010; 37: 198-216.

9. Sen J, Mondal N. Socio-economic and demographic factors affecting the Composite Index of Anthropometric Failure (CIAF). Ann Hum Biol, 2012; 39: 129-36.

10. Antony GM, Laxmaiah A. Human development, poverty, health \& nutrition situation in India. Indian J Med Res, 2008; 128: 198-205.

11. Khor GL. Food-based approaches to combat the double burden among the poor: Challenges in the Asian context. Asia Pac J Clin Nutr, 2008;17: 111.

12. Cheah WL, Wan Muda WA, Mohd Hussin ZA, Thon CC. Factors associated with under-nutrition among children in a rural district of Kelantan, Malaysia. Asia Pac J Public Health, 2010;24: 330.

13. Roy NC. Use of Mid-upper Arm Circumference for Evaluation of Nutritional Status of Children and for Identification of High-risk Groups for Malnutrition in Rural Bangladesh. J Health Popul Nutr, 2000; 18: 171-180.

14. Sen J, Mondal N. Fat mass and fat-free mass as indicators of body composition among Bengalee Muslim children. Ann Hum Biol, 2013; 40: 286.

15. Sen J, Mondal N, Dey S. Assessment of the nutritional status of children aged 5-12 years using upper arm composition. Ann Hum Biol, 2011;38: 752-759.

16. World Health Organization (WHO). WHO child growth standards: head circumference-for-age, arm circumference-forage, triceps skinfold-for-age and subscapular skinfold-for-age: methods and development, 2007.

17. Sen J, Dey S, Mondal N. Conventional nutritional indices and Composite Index of Anthropometric failure: which seems more appropriate for assessing under-nutrition among children? A crosssectional study among school children of the Bengalee Muslim Population of North Bengal, India. Italian J Pub Health, 2011; 8: 66-79.

18. Choudhury KK, Hanifi MA, Rasheed S, Bhuiya A. Gender inequality and severe malnutrition among children in a remote rural area of Bangladesh. $J$ Health Popul Nutr, 2000;18:123-30.

19. Dairo MD, Fatokun ME, Kuti M. Reliability of the Mid Upper Arm Circumference for the Assessment of Wasting among Children Aged 12-59 Months in Urban Ibadan, Nigeria. Int J Biomed Sci, 2012; 8: 140-3.

20. de Onis M, Yip R, Mei Z. The development of MUAC-for-age reference data recommended by a WHO Expert Committee. Bull World Org, 1997; 75: 11-18.

21. Chiabi A, Tchokoteu PF, Takou V, Fru F, Tchouine F. Anthropometric measurements of 
children attending a vaccination clinic in Yaounde, Cameroon. Afr Health Sci, 2008; 8:174-9.

22. Gewa C.A., Oguttu M., Yandell N.S. Maternal nutrition in rural Kenya: health and sociodemographic determinants and its association with child nutrition. Matern Child Nutr 2012; 8: 275-86.

23. Nyaruhucha CN, Mamiro PS, Kerengi AJ, Shayo NB. Nutritional status of underfive children in a pastoral community in Simanjiro district, Tanzania. Tanzan Health Res Bull, 2006; 1: 32-6.

24. Bisai S. Nutrition status based on mid upper arm circumference among urban, poor pre-school children in north 24 Parganas, West Bengal, India. Ser J Exp Clin Res, 2010; 11: 141-145.

25. Biswas S, Bose K, Mukhopadhyay A, Bhadra M. Midupper arm circumference based under nutrition among Bengalee children of Chapra, West Bengal, India. Iran J Pediatr, 2010; 20: 63-68.

26. Das S, Banik SD, Bose K. Mid-upper arm circumference for age and undernutrition among 2 to 6 year old Bauri and Santal children of Purulia, West Bengal, India. Hum Bio Rev 2013: 2: 359372.

27. Kaur G, Sing Kang H, Singal P, Sing S.P. Nutritional status: Anthropometric perspective of preschool children. Anthropologist 2005;7:99-103.

28. Mandal G, Bose K. Assessment of under-nutrition by mid-upper arm circumference among Preschool children of Arambag, Hooghly District, West Bengal, India: An observational study. The Intr J Pedtr Neonatol, 2009; 11: 1.

29. Mishra B, Mishra S. Nutritional anthropometry and preschool child feeding practices in working mothers of central Orissa. Stud Home Comm Sci, 2007; 2: 139-144.

30. Maiti S, De D, Ali KM, Ghosh A, Ghosh D, Paul S. Evaluation of Nutritional Status by Mid-Upper Arm Circumference amongst affluent children. $J$ Nepal Paediatr Soc 2012; 32: 113-116.

31. Mondal N, Engtipi L. Use of Mid upper-arm circumference-of-age (MUAC-for-age) as a screening measure of Wasting: A case of undernutrition among Karbi Tribal children (1-5 years) of Assam, Northeast India. Tribal Health Bull, 2014;21:(in press).

32. Barkley J, Newton C, Maitland K. Severe malnutrition assessment in children in rural Kenya. JAMA, 2005; 294: 2577.

33. Briend A, Maire B, Fontaine O, Garenne M. Midupper arm circumference and weight-for-height to identify high-risk malnourished under-five children. Matern Child Nutr, 2012; 8: 130-133.

34. Feferbaum R, Delgado A.F, Zamberlan P, Leone C. Challenges of nutritional assessment in pediatric ICU. Curr Opin Clin Nutr Metab Care, 2009; 12: 245-50.
35. Joseph B, Rebello A, Kullu P, Raj VD. Prevalence of Malnutrition in Rural Karnataka, South India: A Comparison of Anthropometric Indicator. J Health Popul Nutr,2002; 20: 239-44.

36. Bhadra RK, Chakraborty S. Cultural dimension of health of tea labourers in West Bengal. In. Bhadra RK, Bhadra M, editors. Plantation labours of north-east India. Dibrugarh: NL Publishers, 1997: 199-212.

37. Touitou Y, Portaluppi F, Smolensky MH, Rensing L. Ethical principles and standards for the conduct of human and animal biological rhythm research. Chronobiol Int, 2004; 21: 161-170.

38. Weiner JS, Lurie JA. Practical human biology. London: Academic Press, 1981.

39. Ulijaszek SJ, Kerr DA. Anthropometric measurement error and the assessment of nutritional status. Br J Nutr 1999; 82: 165-177.

40. Mishra D, Singh HP. Kuppuswami's socioeconomic status scale - A revision. Indian $J$ Pediatr 2003; 70: 273-274.

41. James WPT, Mascie-Taylor CGN, Norgan NG, Bristrian BR, Shetty P, Ferro-Luzzi, A. The value of arm circumference measurements in assessing chronic energy deficiency in Third World adults. Eur J Clin Nutr, 1994; 48: 883-894.

42. Chakraborty S, Ghosh R, Bharati P. Breastfeeding practices and nutritional status of preschool children among the Shabar tribal community in Orissa, India. Proceedings of National Symposium, Regional Medical Research Centre for Tribals, Indian Council of Medical Research, Jabalpur, 2006: 227-234.

43. Kikafunda JK, Walker AF, Collett D, Tumwine JK. Risk Factors for Early Childhood Malnutrition in Uganda. Pediatrics, 1998; 51: 72-77.

44. Sharma KR. Malnutrition in children aged 6-59 months in Mugu district. J Nepal Health Res Counc, 2012; 10: 156-9.

45. Sen B, Bose K, Shaikh S, Mahalanabis D. Prediction equations for body-fat percentage in Indian infants and young children using skinfold thickness and mid-arm circumference. J Health Popul Nutr, 2010; 28: 221-229.

46. Borooah VK. Gender bias among children in India in their diet and immunisation against disease. Soc Sci Med 2004; 58: 1719-1731.

47. Sandiford P, Cassel J, Sanchez G, Coldham C. Does intelligence account for the link between maternal literacy and child survival? Soc Sci Med, 1997; 45: 1231-9.

48. Sinnaeve O, Testa J, Ablefonlin E, Ayivi B. Epidemiologic aspects of infant-juvenile malnutrition in Cotonou, Benin. Med Trop (Mars), 2006; 66: 177-81. 